\title{
A critical analysis of intellectual capital research in universities
}

\author{
Constantin BRATIANU \\ The Bucharest University of Economic Studies, Bucharest, Romania \\ constantin.bratianu@gmail.com
}

\begin{abstract}
Researching on the intellectual capital in universities is a challenging task due to the complexity of the intellectual processes within any university and the fuzziness of the basic concepts and methodologies developed so far. Universities are among the oldest social institutions and they concentrate high densities of intellectual capital. The concept of intellectual capital has been created as a result of increasing significantly the role of intangibles in economy and of the dramatic split between the book value and market value of the new companies based on intensive knowledge processes. Intellectual capital represents that component of the total capital of any organization which incorporates all intangible resources and their transformations. Intellectual capital is highly nonlinear by comparison with the capital containing tangible resources, which has a linear structure and Newtonian dynamics. The canonical structure of the intellectual capital is composed of human capital, structural capital, and relationship capital. This structural model has been used extensively in evaluating and reporting the intellectual capital of organizations, including universities. However, the Newtonian paradigm constitutes an important limitation in understanding properly both the nature of intellectual capital and how to manage it efficiently. Our research question is focused on how we can change that paradigm with a better one able to represents more adequately the nature and the basic structure of the intellectual capital. The methodology we used is based on in depth literature analysis, metaphorical thinking, critical thinking, and the multifield theory of knowledge. As a result of our research, this paper presents a new approach of the intellectual capital and its application to the universities.
\end{abstract}

Keywords: intellectual capital, human capital, structural capital, relational capital, rational capital, emotional capital, spiritual capital.

\section{Introduction}

The concept of intellectual capital (IC) started as a promising discovery of the hidden potential of a company which contributes to its competitive edge (Edvinsson \& Malone, 1997; Roos et al., 1997; Stewart, 1997, and Sveiby, 1997), and today it is at cross-roads due to its fuzziness and semantic dynamics (Dumay, 2013, 2016; Edvinsson, 2013). The concept integrates the idea of capital which reflects a tangible entity with the idea of being intellectual, which reflects an intangible entity, and this contrasting nature generated many debates of what actually the intellectual capital can be.

In its pioneering research, Stewart (1997, p. x) explained that in his view, "Intellectual capital is the sum of everything everybody in a company knows that gives it a competitive edge. Unlike the assets with which business people and accountants are familiar - land, factories, equipment, cash - intellectual capital is intangible". More precisely, "Intellectual capital is intellectual material - knowledge, information, intellectual property, experience - that can be put to use to create wealth" (Stewart, 1997, p. x). More recently, Dumay (2016) considers that in this definition we should change the idea of wealth creation with that of value creation since "we can define wealth creation as increasing the stock of money or something convertible into money. However, we cannot always use money as a measurement unit for IC or the outputs of managing IC. Therefore, I 
argue that changing IC's definition makes it more relevant to the way researchers and practitioners (should) apply IC". Edvinsson (2013, p. 164) emphasizes that the original purpose of the Skandia IC Navigator was "an attempt to visualize the hidden value, rather than account for, intangibles". Stressing the intangible nature of the intellectual capital, Edvinsson (2013, p. 165) remarks that "IC is about the future. IC is also, from a systems science perspective, a larger concept. It contains precise components, such as intellectual property (IP) and IP rights, which are legally packaged and protected intangible assets, as value logic. But it also incorporates knowledge, in a much broader sense". That knowledge should be transformed into value for the organization and further, for society. Extending the view to all intangible elements which are at the core of the knowledge economy, Edvinsson (2002) underlines their importance in achieving the competitive advantage, and the need to change the whole paradigm of value creation in order to understand the future of economic development. "The fact is that the nature of competitive advantage has shifted from the physical to the intangible; the visible to the invisible; the seen to the unseen. The nature of value creation is going through a paradigm change" (Edvinsson, 2002, p. 21).

This Edvinssonian vision about the intellectual capital couldn't be capture into the linear thinking models of many researchers and due to the intrinsic ambiguity nature of the intellectual capital, research has been directed more towards measuring and reporting the intellectual capital than to its role in achieving a competitive advantage in the knowledge economy. In many recently published papers, the authors explain this phenomenon and suggest new ways to un-lock the intellectual capital research (Borin \& Donato, 2015; Chiuchi \& Dumay, 2015; Dumay, 2009, 2013; Habersam et al., 2018). Dumay (2009, p. 205) remarks that many researchers start to investigate the intellectual capital of a certain organization having an "accounting" model in mind: "The view offered in this paper is that these contemporary IC measurement frameworks are reifying IC in the same manner in which tangible assets are portrayed within accounting, which is akin to attempting to make intangible tangible. This is what the author defines as an "accountingisation" of IC".

The purpose of this paper is to analyze critically how these thinking models used for the intellectual capital research have been reflected in the research of the university intellectual capital. Also, what are the outcomes and consequences of these intellectual capital models when applied to universities. In the next section we are going to explore a significant literature background, and then to present our research methodology. Next, the paper will present our findings, and some conclusions in the final part of the paper.

\section{Literature review}

In the knowledge economy (Hadad, 2017; Powell \& Snellman, 2004; Sveiby, 1997), the role of universities becomes critical, since they have to develop significantly their dynamic capability (Teece, 2009) of becoming learning organizations and creating generic knowledge (Senge, 1999). For a company to transform into a learning organization it is necessary that organizational learning (Argote, 1999) and intergenerational learning (Lefter et al., 2011) to embrace the whole organization by moving fast along the ontological axis of knowledge dynamics process explained by Nonaka and Takeuchi (1995).

Universities are among the oldest social institutions of society, leading among other effects to a large inertial thinking (Bratianu, 2007) and resistance to change, but the 
increasing competition on the higher education services market and the needs of society are powerful driving forces for their transformation into learning organizations, a process which is supported by their intellectual capital. These changes have been requested also by the whole Bologna process for the European universities (Dima, 2014), changes which affected also the governance systems of many of them (Bratianu \& Pinzaru, 2015). As underlined by Secundo et al. (2015, p. 419), "In research centers and universities, the key issue at stakes is the effective management of intangible assets and IC, which constitute the largest proportion of universities' assets.

Most contributions in the literature background of the intellectual capital of universities come from the European universities, and they are focused mainly on empirical research performed in Spain, Austria and Italy. The Spanish experience is based on the research performed by the Autonomous University of Madrid (AUM), as a pilot university in the PRIME Network of Excellence and the Observatory of European Universities (OEU). Fifteen universities and research institutes from eight European countries work together in a research project on the intellectual capital of universities. Their purpose was to "develop a common framework and build a battery of indicators to measure and compare the intangible elements related to research activities. Its main objective was to provide universities and research centers with the necessary tools for the governance of research activities" (Sanchez et al., 2007, p. 5). After the researchers develop a battery of indicators, they tested that battery within the AUM and analyzed the final results. They reached the conclusion that there were too many indicators, measuring both tangible and intangible entities. Also, many indicators have fuzzy formulations which created difficulties in evaluating them in different universities.

The Austrian experience with intellectual capital of universities is unique since it has been generated by legislation, as a compulsory reporting (Habersam et al., 2013; Habersam et al., 2018; Leitner, 2004; Piber \& Pietsch, 2006). The Ministry of Education initiated in 2002 a higher education reform leading to the universities' autonomy. As Habersam et al. (2013, p. 324) explain, "Before 2002, the rector and vicerectors of Austrian public universities acted more as an administrative than a managerial body. Internal management structure, decision-making arrangements and leadership roles and the relationship between these internal functions and the role of governing body have been determined by a culture of 'collegium' and 'bureaucracy'". By this new legislation, the Ministry granted full autonomy to all state universities. However, this autonomy should be coupled with a new form of accountability, and thus the Ministry introduced by law the Knowledge Balance Sheet (KBS) as a form of intellectual capital reporting. "The reporting framework (the university to the Ministry) consists of two annual procedure: (1) the financial statement of accounts and (2) the KBS, which includes a report on yearly achievements in accordance with the performance agreements for a three-year period. The Ministry considers the latter to be of specific importance for purposes of accountability" (Habersam et al., 2013, p. 324). The first version of the KBS contained a descriptive part and an evaluation based on 53 indicators. Since there were many complains from the universities concerning the ambiguity and irrelevance of some indicators, The Ministry improved the KBS structure and reduced the total number of indicators to 26 . 
In a comprehensive analysis of the whole process of intellectual capital reporting of the Austrian universities for the last ten years based on the compulsory knowledge balance sheets, Habersam et al. $(2018,48)$ emphasize the fact that "Enforced 'accountingisation' in its purest form will no longer be accepted by universities which complain about a negative cost-benefit ratio. Indicators need to be convincing in order to be accepted". The KBS should change the focus from reporting to a strategic process of using more efficiently the intangible resources a university may have. "Within this context of enforced legitimation, the lack of a value-driven strategy formulation becomes a disadvantage. We conclude that an explicit strategy and declared political will may provide sufficient orientation for the sense making on an organizational and national level" (Habersam et al., 2018, p. 47). In a strategic perspective, the focus should be on achieving a competitive advantage and the defined strategic goals, by an intelligent way of allocating the university resources.

The Italian experience with the intellectual capital of universities have been analyzed mostly by Secundo et al. (2014), Secundo et al. (2015), and Secundo et al. (2017). The intellectual capital evaluation and reporting is based on the same principles and results are quite similar to those discussed above. However, this reporting is not enforced by law. As a new perspective resulted from an European research project, Secundo et al. (2015, p. 434) describe an Intellectual Capital Maturity Model (ICMM) which can be viewed as a "high level strategy rather than a new IC model, since it can be implemented also in the context of organizations already using some particular model framework. The ICMM sustains the understanding of the actual impact of IC in action when moving from lower level to the higher level, and allows the assessment of IC value at university level to provide insights for all stakeholders involved in the decision-making process".

\section{Methodology}

The methodology designed for this conceptual research is based on three pillars: a critical analysis of the literature background concerning the intellectual capital of universities, a metaphorical analysis of the basic concepts used in knowledge dynamics and intellectual capital research, and a significance analysis of the indicators used for evaluation and reporting the intellectual capital of universities.

We perform a critical analysis of the literature background following the principles of the qualitative research (Bryman \& Bell, 2007; Maxwell, 2013). We analyzed all the papers dealing with the intellectual capital research in universities published in the main stream international journals, and some book chapters on that topic. For analysis we consider the conceptual framework of the intellectual capital defined in some of the most appreciated books (Andriessen, 2004; Edvinsson \& Malone, 1997; Roos et al., 2005; Ricceri, 2008; Stewart, 1997; Sveiby, 1997), and some well-known European Projects (MERITUM, 2002; METI, 2005; Mouritsen et al., 2003). We used the metaphorical analysis for explaining different interpretations for intellectual capital, from semantic and practice viewpoints. Metaphorical thinking (Andriessen, 2006; Lackoff \& Johnson, 1999) demonstrates that metaphors play an essential rol in understanding abstract concepts reflecting intangible entities like knowledge and intellectual capital.

We analyzed the canonical model of the intellectual capital (Andriessen, 2004; MERITUM, 2002; Viedma, 2003) and how it is used in practice to evaluate the intellectual 
capital by using indicators, and what is the relevance of these indicators when people measure and report results of these measurements based on different indicators. We focused especially on the Austrian experience since the evaluation procedure is welldocumented in the legislation (Federal Law Gazette of the Republic of Austria, 2006; Habersam et al., 2013, 2018; Piber \& Pietsch, 2006).

\section{Results and discussions}

We considered for reference the definition of intellectual capital given by Stewart (1997), presented in the beginning of the paper and that give by Roos et al. (2005, p. 19): "Intellectual capital (IC) can be defined as all nonmonetary and nonphysical resources that are fully or partly controlled by the organization and that contribute to the organization's value creation". The essence of both definitions is clear: the intellectual capital constitutes an integration of intangible resources, which are owned and controlled only partly by an organization. For instance, the experience of employees which produce the tacit knowledge cannot be owned and controlled by the company, but it can be used if there is an adequate rewarding system for all employees.

According to the canonical model, the intellectual capital is composed of human capital, structural or organizational capital, and relational capital. Human capital is defined as "the knowledge that employees take with them when they leave the firm. It includes the knowledge, skills, experiences and abilities of people. Some of this knowledge is unique to the individual, some may be generic" (Ricceri, 2008, p. 39). Many experts consider that human capital is the most important component of the organizational intellectual capital since it is the only one capable of creating knowledge. Structural capital or organizational capital is defined as "the knowledge that stays within the firm at the end of the working day. It comprises the organizational routines, procedures, systems, cultures, databases etc." (Ricceri, 2008, p. 39). Structural capital is important since it can stimulate or diminish the contribution of human capital to the operational level of the intellectual capital, and through this component to the performance of the company. Finally, the relational capital is defined as containing "all resources linked to the external relationships of the firm, with customers, suppliers or R\&D partners" (Ricceri, 2008, p. 39). As shown by Viedma (2003), this canonical model has got several shortcomings: a) it is a static model, although many organizational processes are dynamic; b) the model does not contain any feature linked to the strategy of the company; c) although it is simple and intuitive, the model is not logically consistent since the three basic entities are not completely independent.

The canonical model has been used extensively in conceiving the regulation on intellectual capital reports for the Austrian universities (Intellectual Capital Report Act ICRA). According to the ICRA, "The intellectual capital report aims at presenting, evaluating and communicating intangible assets, performance processes and their consequences and serves as a qualitative and quantitative basis for generating and entering a performance agreement" (ICRA, 2006, p. 1). The document defines the specific indicators to be used for measuring the human capital, structural capital and relational capital of the university. Analyzing these indicators with respect to their relevance for the intellectual capital of the university we reached the conclusion that they represent tangible resources, which are in 
conflict with the semantic of the intellectual capital concept. Also, most of these indicators have no relevance for the real intellectual capital of the university.

In the section II.1 - Intellectual property - human capital, of the ICRA, the indicators are represented by pure numbers of different categories of staff. For instance: Number of awarded teaching qualifications (habilitations), number of appointments to the university, number of incoming academic staff, number of participants in programs for continuing education and personnel development etc. These numbers reflect different categories of people and cannot constitute a measure of the intellectual capital which contains knowledge, ideas and similar intangible entities. It is a wrong understanding of the nature of intellectual capital. In section II.2 - Intellectual property - structural capital, we can find indicators like: funding for measures promoting equal opportunities for men and women and affirmative action for women in Euro, funding for measures advancing gender specific education and research/development and promotion of the arts in euro, number of staff active at special institutions, cost for available online research data bases in euro, floor space in square meters. These numbers have nothing to do with structural capital and especially with the idea of intellectual capital. The last indicator is a nonsense with respect to the meaning of intellectual capital. In the first revision of these indicators, this floor space indicator has been removed (Habersam et al., 2018), but the simple presence in the first case demonstrates that the knowledge balance sheet is in fact a kind of inventory used in managerial audit and has nothing in common with the idea of intellectual capital.

In their critical analysis of the enforced process of intellectual capital reporting by the Austrian universities in the last ten years, Habersam et al. (2018, p. 46) conclude: "Insufficient relevance of the KBS for internal managerial control in universities results in an inefficient and ineffective allocation of the scarce resources 'time' and 'awareness' especially in the administrative departments of the universities. Data collection dominates, whereas the more important activity would be to support organizational sense making by discussing strategic goals, possible actions and their consequences for different stakeholders".

The phenomenon of "accountingisation" described by Dumay (2009) demonstrates the captivity of people researching on intellectual capital in linear thinking (Bratianu, 2007, 2009). However, intellectual capital is nonlinear and the metrics used for its evaluation should be based on nonlinear thinking models and on knowledge dynamics models (Bratianu, 2010, 2011a). Moreover, the multifield theory of knowledge (Bratianu, 2011a, 2013) shows that knowledge should be interpreted metaphorically as a multifield composed of rational, emotional, and spiritual knowledge. Starting from here it can be demonstrated that the canonical model of the intellectual capital can be refined down to the basic components: rational intellectual capital, emotional intellectual capital, and spiritual intellectual capital (Bratianu, 2011b).

For a better understanding of the intellectual capital of the universities we should come back to the vision of Edvinsson $(2002,2013)$ and to look strategically to the future. Universities should develop strategies to achieve their competitive advantage by using more intelligently their intellectual capital potential (Bejinaru, 2017; Bratianu \& Bejinaru, 2017; Bratianu \& Bolisani, 2015; Dima et al., 2016). 


\section{Conclusion}

Intellectual capital of the universities represents an important domain for research since universities are organizations with a very high density of intellectual capital, which determines their competitiveness on the global higher education services. However, the concept of intellectual capital is fuzzy and creates real difficulties in understanding its nature and designing adequate metrics for its evaluation.

Although the pioneers of intellectual capital like Thomas Stewart, Leif Edvinsson, Karl Eric Sveiby and Goran Roos showed that intellectual capital contains intangible resources, many researchers today use metrics containing indicators for tangible entities and linear rules for aggregating them. There is a whole phenomenon of "accountingisation" the intellectual capital which is based on linear thinking and accounting experience. That becomes irrelevant when applied to universities, as the ten years of Austrian experience demonstrated clearly.

The intellectual capital of universities needs a new vision, based on the multifield theory of knowledge and strategic thinking. Knowledge should be considered in its complexity as rational, emotional, and spiritual knowledge, and according to the entropic perspective we should understand the possibility of transforming one form of knowledge into another form. From a very practical point of view, in a university with a high intellectual potential, performance can be obtained if and only if there is an adequate system of motivating people to create and transfer knowledge, which means an efficient knowledge dynamics process.

\section{References}

Andriessen, D. (2004). Making sense of intellectual capital: designing a method for the validation of intangibles. Amsterdam: Elsevier.

Andriessen, D. (2006). On the metaphorical nature of intellectual capital: a textual analysis. Journal of Intellectual Capital, 7(1), 93-110.

Argote, L. (1999). Organizational earning: creating, retaining and transferring knowledge. $2^{\text {nd }}$ Edition. New York, NY: Springer.

Bejinaru, R. (2017). Knowledge strategies aiming to improve the intellectual capital of universities. Management \& Marketing. Challenges for the Knowledge Society, 12(3), 500-523.

Borin, E., \& Donato, F. (2015). Unlocking the potential of IC in Italian culture. Journal of Intellectual Capital, 16(2), 285-304.

Bratianu, C. (2007). Thinking patterns and knowledge dynamics. In Martins, B., \& Remenyi, D. (Eds.). Proceedings of the $8^{\text {th }}$ European Conference on Knowledge Management, 6-7 September 2007. Consorci Escola Industrial de Barcelona, Barcelona, Spain (pp. 152157). Reading, UK: Academic Conferences.

Bratianu, C. (2009). The frontier of linearity in the intellectual capital metaphor. In Stam, C. \& Andriessen, D. (Eds.). Proceedings of the European Conference on Intellectual Capital, Inholland University of Applied Sciences, Haarlem, The Netherlands, 28-29 April 2009 (pp. 97-103). Reading, UK: Academic Conferences and Publishing International. 
Bratianu, C. (2010). A critical analysis of Nonaka's model of knowledge dynamics. In Rodrigues, S. (Ed.). Proceedings of the $2^{\text {nd }}$ European Conference on Intellectual Capital, ISCTE Lisbon University Institute, Lisbon, Portugal, 29-30 March 2010 (pp.115-120). Reading, UK: Academic Conferences and Publishing International.

Bratianu, C. (2011a). Changing paradigm for knowledge metaphors from dynamics to thermodynamics. System Research and Behavioral Science, 28, 160-169.

Bratianu, C. (2011b). A new perspective of the intellectual capital dynamics in organizations. In Vallejo-Alonso, B., Rodriguez-Castellanos, A., Arregui-Ayastuy, G. (Eds.). Identifying, measuring, and valuing knowledge-based intangible assets: new perspectives (pp. 1-21). Hershey, PA: IGI Global.

Bratianu, C. (2013). The triple helix of the organizational knowledge. Management Dynamics in the Knowledge Economy, 1(2013), 207-220.

Bratianu, C., \& Bejinaru, R. (2017). Knowledge strategies for increasing IC of the universities. In Lopez, I.T., \& Serrasqueiro, R. (Eds.). Proceedings of the $9^{\text {th }}$ European Conference on Intellectual Capital, ECIC 2017 (pp.34-42). Instituto Universitario de Lisboa (ISCTEIUL), Lisbon, Portugal, 6-7 April 2017. Reading, UK: Academic Conferences and Publishing International.

Bratianu, C., \& Bolisani, E. (2015). Knowledge strategies: an integrated approach for managing uncertainty. In Massaro, M., \& Garlatti, A. (Eds.). Proceedings of the $16^{\text {th }}$ European Conference on Knowledge Management, University of Udine, Italy, 3-4 September 2015 (pp. 169-177). Reading, UK: Academic Conferences and Publishing International.

Bratianu, C., \& Pinzaru, F. (2015). University governance as a strategic driving force. In Rouco, J.C.D. (Ed.). Proceedings of the $11^{\text {th }}$ European Conference on Management, Leadership and Governance (pp. 28-35). Military Academy, Lisbon, Portugal, 12-13 November 2015. Reading, UK: Academic Conferences and Publishing International.

Bryman, A. \& Bell, E. (2007). Business research methods. Second edition. Oxford, UK: Oxford University Press.

Chiuchi, M.S., \& Dumay, J. (2015). Unlocking intellectual capital. Journal of Intellectual Capital, 16(2), 305-330.

Dima, A.M. (2014). Trends in European higher education convergence. Hershey, PA: IGI Global.

Dima, A.M., Hadad, S., \& Cantaragiu, R. (2016). A conceptual analysis of business-university knowledge transfer in the energy field. In Tantau, A., \& Hadad, S. (Eds.). Proceedings of the 10 th International Conference on Business Excellence (pp. 199-204). Bucharest University of Economic Studies, Bucharest, Romania, 3-4 March 2016. Bucharest: ASE Publishing House.

Dumay, J. (2009). Intellectual capital measurement: a critical approach. Journal of Intellectual Capital, 10(2), 190-210.

Dumay, J. (2013). The third stage of IC: towards a new IC future and beyond. Journal of Intellectual Capital, 14(1), 5-9.

Dumay, J. (2016). A critical reflection on the future of intellectual capital: from reporting to disclosure. Journal of Intellectual Capital, 17(1), 168-184.

Edvinsson, L. (2002). Corporate longitude - navigating the knowledge economy. London: Pearson. 
Edvinsson, L. (2013). IC 21: reflections from 21 years of IC practice and theory. Journal of Intellectual Capital, 14(1), 163-172.

Edvinsson, L., \& Malone, M. (1997). Intellectual capital -realizing your company's true value by finding its hidden brainpower. New York, NY: Harper Business.

Federal Law Gazette of the Republic of Austria (2006). Regulation of the Federal Ministry of Education, Science and Culture on Intellectual Capital Reports (Intellectual Capital Report Act - ICRA).

Habersam, M., Piber, M., \& Skoog, M. (2018). Ten years of using knowledge balance sheets in Austrian public universities: a retrospective and prospective view. Journal of Intellectual Capital, 19(1), 34-52.

Habersam, M., Piber, M., \& Skoog, M. (2013). Knowledge balance sheets in Austrian universities: the implication, use, and re-shaping of measurement and management practices. Critical Perspectives on Accounting, 24(4/5), 319-337.

Hadad, S. (2017). Strategies for developing knowledge economy in Romania. Management \& Marketing. Challenges for the Knowledge Society, 12(3), 416-430.

Lakoff, G., \& Johnson, M. (1999). Philosophy in the flesh: the embodied mind and its challenge to the western thought. New York, NY: Basic Books.

Lefter, V., Bratianu, C., Agapie, A., Agoston, S., \& Orzea, I. (2011). Intergenerational knowledge transfer in the academic environment of knowledge-based economy. Amfiteatru Economic, 13(30), 307-319.

Leitner, K.H. (2004). Valuation of intangibles. Intellectual capital reporting for universities: conceptual background and application for Austrian universities. Research Evaluation, 13(2), 129-140.

Maxwell, J.A. (2013). Qualitative research design. An interactive approach. Third Edition. Los Angelos, CA: SAGE.

MERITUM (2002). Guidelines for managing and reporting of intangibles. Madrid: Fundacion Airtel Movil.

METI (2005). Guidelines for disclosure of intellectual capital assets based management. Ministry of Economy, Trade and Industry, Japan.

Mouritsen, J., Bukh, P., Flagstad, K. (2003). Intellectual capital statements: the new guidelines. Danish Ministry of Science, Technology and Innovation.

Nonaka, I., \& Takeuchi, H. (1995). The knowledge-creating company. How Japanese companies create the dynamics of innovation. Oxford, UK: Oxford University Press.

Piber, M., \& Pietsch, G. (2006). Performance measurement in universities: the case of knowledge balance sheets analyzed from a new institutional perspective. In Epstein, M. \& Manzoni, J.F. (Eds.). Performance measurement and management control: improving organizations and society. Amsterdam: Elsevier, 397-422.

Powell, W.W., \& Snellman, K. (2004). The knowledge economy. Annual Review of Sociology, $30,199-220$.

Ricceri, F. (2008). Intellectual capital and knowledge management: strategic management of knowledge resources. London, UK: Routledge.

Roos, G., Roos, J., Dragonetti, N., \& Edvinsson, L. (1997). Intellectual capital: navigating the new business landscape. New York, NY: University Press.

Roos, G., Pike, S., \& Fernström, L. (2005). Managing intellectual capital in practice. Amsterdam: Elsevier. 
Sanchez, P., Elena, S., \& Castrillo, R. (2007). The ICU report: an intellectual capital proposal for university strategic behavior. Proceedings of the IMHE Conference. Paris: OECD.

Secundo, G., De Beer, C., Schutte, C.S.L., \& Passiante, G. (2017). Mobilizing intellectual capital to improve European universities' competitiveness: the technology transfer offices' role. Journal of Intellectual Capital, 18(3), 607-624.

Secundo, G., Elena Perez, S., Martinaitis, Z., \& Leitner, K.H. (2014). Intellectual capital

PICBE $\mid 160$ management in European universities in times of change: an IC maturity model. IFKAD, University of Basilicata, Italy, 11-13 June 2014, Matera, pp. 1095-1113.

Secundo, G., Elena Perez, S., Martinaitis, Z., \& Leitner, K.H. (2015). An intellectual capital maturity model (ICMM) to improve strategic management in European universities: a dynamic approach. Journal of Intellectual Capital, 16(2), 419-442.

Senge, P. (1999). The fifth discipline: the art \& practice of the learning organization. New York, NY: Random House.

Stewart, T. (1997). Intellectual capital: the new wealth of organization. New York, NY: Doubleday.

Sveiby, K.E. (1997). The new organizational wealth: managing and measuring knowledge based assets. San Francisco, CA: Berrett-Koehler.

Teece, D.J. (2009). Dynamic capabilities \& strategic management: organizing for innovation and growth. Oxford, UK: Oxford University Press.

Viedma, J.M. (2003). In search of intellectual capital general theory. Electronic Journal of Knowledge Management, 1(2), 213-226. 